\title{
Absenteeism of Medical Students from Subspecialty Clinical Rotations: A Qualitative Study
}

\author{
Shahadat Hussain Chaudhry ${ }^{1}$ and Javed Iqbal2
}

\begin{abstract}
Objective: To explore in depth the phenomena of low attendance in subspecialty clinical ward rotation and how it can be improved among $4^{\text {th }}$ year MBBS medical students.

Study Design: Constructivist paradigm using qualitative transcendental phenomenological research design.

Place and Duration of Study: Quaid-e-Azam Medical College, Bahawalpur, Pakistan, from February to March 2017.

Methodology: Two audio recorded focus group discussions (FGDs) of 4th year MBBS class consisting of six medical students ( 3 males and 3 females) were conducted using maximum variance purposeful sampling method based on students' performances. Group A included students among highest scorers in 2 nd professional examination and group B included poorly performing students. Open-ended unstructured questions were posed in FGDs. Duration of discussion was approximately 45 minutes for each group. The recording was transcribed and analysed with NVivo software using thematic analysis technique generating themes and sub-themes. Member checking and triangulation with frequency of quotes were used for validation.

Results: Students identified faculty related factors as the main theme with environment and students related contributory themes. Subthemes included improper teaching methodology, absence of a formal curriculum and teacher attitudes leading to little learning and students considering attending these wards a waste of time. Improvement suggested as an applied practical subspecialty curriculum implementation, continuing medical education for faculty development, effective interactive teaching/training strategies and record keeping.

Conclusion: This study found that the main reason of medical students' low attendance was faculty related factors. Continued professional development of faculty may help improve subspecialty clinical training.
\end{abstract}

Key Words: Absenteeism, Subspecialty, Clinical clerkship, Clinical competency, Medical students, Clinical education.

\section{INTRODUCTION}

Pakistan Medical and Dental Council (PMDC) and Higher Education Commission (HEC) are the regulatory authorities for undergraduate medical education and define the competencies required of the graduating doctors in Pakistan. ${ }^{1}$ Curriculum is designed to include basic medical sciences only in the first two years; with gradual escalation from basic to clinical sciences only in advanced years. Third, fourth and final years clinical clerkships include general medicine, general surgery, pediatrics, gynecology and obstetrics. Fourth year curriculum includes additional clinical clerkships with subspecialty clinical rotations in cardiology, psychiatry, pulmonology, dermatology, nephrology, orthopedics, neurosurgery and urology wards. ${ }^{2}$ Low attendance and high absenteeism in the subspecialty clinical rotations among fourth year medical students have been observed.

Low attendance of medical students in lectures and wards is not a new problem as different reasons have

Department of Cardiologyl / Surgery², Quaid-e-Azam Medical College, Bahawalpur, Pakistan

Correspondence: Dr. Shahadat Hussain Chaudhry, Department of Cardiology, Quaid-e-Azam Medical College, Bahawalpur, Pakistan

E-mail:drshahadat@hotmail.com

Received: April 25, 2018; Accepted: September 03, 2018 been reported for it. ${ }^{3}$ The attendance of classrooms and clinical clerkships have an impact on medical students' examination grades. Medical students with greater than $80 \%$ attendance in lectures and clinical rotations are more likely to perform well in university examinations. ${ }^{4,5}$ Multiple reasons identified for absenteeism, which are low motivation, prioritising subject/attendance for varying reasons, teaching strategies etc. Whereas, engaging teaching styles with motivational, constructive and applied lectures have a positive impact on students' attendance during clinical clerckships. ${ }^{6}$ Good attendance during clinical clerkships of medical students have vital role for the competency of health professionals. 7,8

Competency-based training in medical education is critical in healthcare delivery. Workplace-based teaching has greater impact in developing clinical competency of medical students. 9 So, regular attendance in subspecialties clinical training is crucial for exposure of relevant areas and competencies. Most of the literature available in this context are cross-sectional surveys and mainly of absenteeism in lectures.

The purpose of this study was to explore in depth minds of fourth year MBBS medical students about low attendance at subspecialty clinical ward rotations in Quaid-e-Azam Medical College, Bahawalpur and measures needed to improve this low attendance. This study will help to identify reasons for the said pheno- 
menon, possibly improve this important area of training and modify the curriculum to this effect.

\section{METHODOLOGY}

This is a qualitative transcendental phenomenological research in constructivist paradigm consisted of two focus group discussions (FGDs). These two FGDs explored in depth the phenomena of low attendance in subspecialty clinical ward rotation among $4^{\text {th }}$ year MBBS medical students of Quaid-e-Azam Medical College, Bahawalpur, Pakistan from February to March 2017 following approval from Institutional Review Board (IRB). Two groups were included from the fourth year MBBS class using maximum variance purposeful sampling based on their performances in second professional examination. Each group consists of six medical students with equal coverage of gender (three female students and three male students). Group A included students among the highest scorers in the second professional examination. Group B included students among the lowest scorers in the second professional examination. The academic records were taken from students' section office of the college and then highest and lowest scorer students' were selected. The students were informed telephonically about the research and meeting place was decided. Those students were excluded who were neither willing to participate nor given consent.

Ethical considerations of anonymity and autonomy were addressed through allocation pseudonyms of $A, B$, $C, D, E$ and $F$ to all participants for each FGD to conceal students' identities in audio recording as well as transcription verbatim. Informed consents were obtained individually as well as grouped after giving brief overview of the topic, objective of research, and ground rules.

This research was done under the supervision of qualified and trained medical educationists. Two facilitators, including the first author, were there, one as moderator and second author as observer. FGDs were conducted in a round table format at Department of Medical Education along with two audio recorders. Unstructured and open-ended questions used in FGDs are given in Table I. Both FGDs were started similar opening question followed by separate discussion on other questions for in-depth mind exploration. Both English and Urdu language were used as medium for FGDs of around 45 minutes each to ensure in-depth mind exploration.

Thematic analysis of qualitative data was done by data reduction and transcribing audio recording. Recordings of FGDs were transcribed in verbatim into English language in Microsoft Word and the transcriptions were validated by all authors to ensure the trustworthiness. Thematic analysis was used through the process of data reduction, sorting, coding and assigning them to categories and themes. NVivo software V.11 was used for qualitative data analysis by importing the transcribed doc. file into the software. Words of answers to research questions with similar meanings were grouped under one theme and sub-themes with minimum overlap. Themes along with sub-themes and trends were triangulated with their respective frequencies of ideas to confirm their accuracy. Result was drawn under three major themes like faculty related, environment related, and students related reasons and their respective subthemes. Themes and sub-themes were revalidated through iterative of revisiting the questions and transcription by all the authors.

\section{RESULTS}

Most of the students expressed their interest in attending subspecialty clinical rotation in response to the opening question of "Are most of students not interested in attending subspecialty clinical rotations?"; and only $20-25 \%$ showed disinterest. Thematic analysis of the FGDs about the reasons of low attendance in subspecialty rotations and how to improve the attendance revealed that faculty, students, and environment related factors were the main theme. Table II shows the themes, sub-themes and comments verbatim about the reasons for low attendance. Table III shows the themes, subthemes and comments verbatim about how to improve this trend. Word cloud (Figure 1) highlighted teacher, training, discourage, curriculum, bedside training and practical etc. as the most frequently used cords. Students stressed more on practical/bedside training,

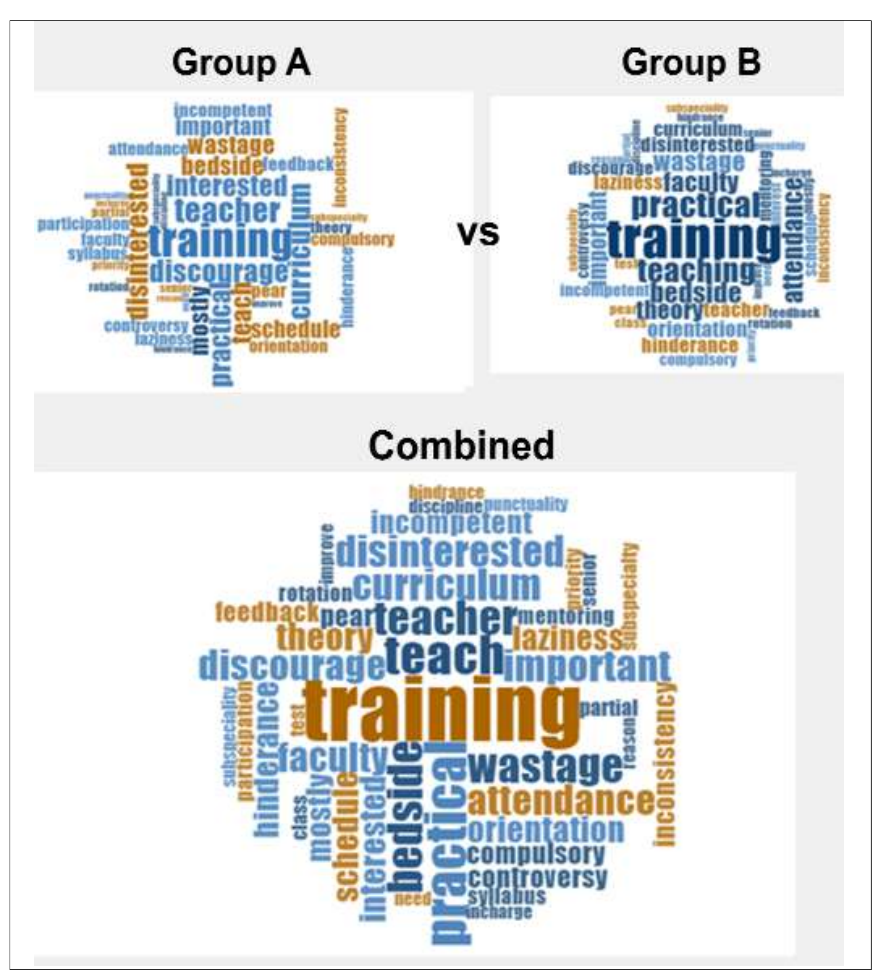

Figure 1: Comparison of word frequency in Focus groups discussion. 
discouraging attitudes by teachers/peers and wastage of time. Faculty related factors were highlighted most in terms of number of quotes for both FGDs, i.e. $83(54.60 \%)$.
Other environmental and student related factors were $43(28.30 \%)$ and $26(17.10 \%)$, respectively. The question about the rectification of absenteeism again showed

Table I: Focus group question guide.

\begin{tabular}{l|l}
\hline Question type & Questions \\
\hline Opening & 1. Do you agree that the students of 4th years MBBS are not interested in attending subspecialty clinical rotation? \\
\hline Key & $\begin{array}{l}\text { 2. In your opinion, why students do not attend subspecialty clinical rotation regularly? } \\
\text { 3. If you are made in-charge, how will you improve it? }\end{array}$ \\
\hline Ending & $\begin{array}{l}\text { 4. Is there any need of subspecialty clinical rotation or affect your training and competency as a doctor?? } \\
\text { 5. At the end, any other comments please? }\end{array}$ \\
\hline
\end{tabular}

Table II: Comments verbatim of theme for absenteeism reasons.

\section{Theme-1 Faculty factors}

\section{Curriculum/Schedule}

1. They don't possess a defined curriculum to teach that such and such things will be taught.

2. Ward rotations are scheduled between lectures. There are 2 lectures then two-hour ward and one-hour lecture again. In this way students lose their interest in the ward.

3. First 3-4 days are spent on history taking. As we are getting to start main things, time for next rotation comes.

\section{Teacher attitude}

4. Teachers try to put responsibility on others.

5. The teachers are disinterested, and they discourage us to attend.

6. I have been discouraged by the teachers and other people for my enthusiasm of learning.

7. They simply say, "What are you doing here?" "You do not have book!" Their attitude is discouraging.

8. Some teachers discourage the students from asking questions.

9. Time is wasted as most of the teachers are an hour late.

10. Some wards just take attendance and send us back.

11. Two and half hour we wander here and there, which is wastage of time.

12. We avoid going to wards when there is a feeling of teacher not being interested.

13. Again, subspecialty wards are not interested in students and students are not interested in ward. It's a cycle.

14. The attitude of the teachers matters a lot.

15. Initial batches are taught better and quality of teaching gets lower with each subsequent batch. Near exam teaching stopped. They get attendance and sent the students back.

16. The main reason is that teachers mostly focus on the final year class. If third year class is there, it gets ignored. Similarly, in medicine and surgery if final year is there then we (4th year) get ignored.

\section{Absence of bedside teaching}

17. We are taught on power point throughout the year in the rotations.

18. We come to wards to learn procedures, we can cover theory from the books.

19. They do not give training of any practical. Only training for history taking

20. In the ward after lecture they should also demonstrate on the patient practically but does not happen.

21. Teacher should make sure that we understand instead of pushing information.

22. First aid training is not provided, which is very important.

23. We should be taught all those things that a house officer should know, or the paramedics are taught.

24. They teach us but not give any practical training.

Inconsistent teaching

25. There is inconsistency in the pattern of teaching. One teacher wants to start the history in one way, whereas another teacher would negate that. It seems departments are not coordinated.

26. There is a different teacher every day and they all started from baseline and spend an hour on history.

Theme-2 Environment factors

Attendance

27. There is no strictness of attendance in some departments and there is no difference among regular and irregular attendees.

28. Neither there are any monthly reports nor there is any information to the parents. Most of the students do not consider attendance to be of any consequence.

Theme-3 Students factors

Students attitude

29. When the students feel that they are not learning, lazy students stop attending wards.

30. Most of the students go back to hostels and rest due to their laziness. .

31. It is our own mistake that we do not go to ward.

32. The students follow their senior peers and their class-fellows and don't go to the wards.

33. Our senior colleagues discourage us that you need not to attend the ward because it is wastage of time.

34. If X-rays are shown then only front few line students can see, students at the back are unable to see X-rays and become disinterested.

35. Students of batches near to the exam time miss the wards for exam preparation. 
Table III: Comments verbatim of themes for improvement in absenteeism.

\section{Theme-1 Faculty factors}

\section{Curriculum/Schedule}

1. Curriculum should be devised of 2 weeks rotations.

2. Teachers should follow the curriculum designed for fourth year students level.

3. Bedside teaching should be conducted, and lectures should be avoided.

4. The curriculum should be displayed and declared.

5. Teachers should be assigned/designated for training

6. I will make the proper schedule and assign same teacher for the whole batch.

7. If more than one teacher is scheduled for training, each teacher should cover the whole topic.

\section{Bedside/practical teaching}

8. Only clinical training should be done in the wards.

9. We want more bedside learning.

10. Hands on practical work should be increased to enhance interest of students.

11. There should be more exposure and interaction with patients, and less interaction with teachers.

12. Teaching style is OK but should be more practical than theory.

13. There should be a lecture on clinical cases and then students should practice them.

\section{Teaching methodology}

14. Teaching methodology should be uniform.

15. Teachers should be more interactive, active participation of the students and less didactic teaching by the teacher. Teacher should guide us rather than teach us.

16. Batch rotations should be such that students feel comfortable attending clinical rotations.

17. Teachers should confirm conceptual understanding and explain to us again if needed but not insult us.

18. Experienced teachers should teach in the evening.

Feedback / assessment

19. Assessment based specific constructive feedback, like you are week in ECG, should be given.

20. End of rotation formative ward tests should be conducted.

21. I think ward test is discouraging for most of the students instead of ward test feedback is much better.

22. Feedback is only possible when you have one teacher who knows the batch very well.

23. There should be post-ward test and report should be sent to university and home, as well.

Faculty training

24. Faculty should be trained to generate interest in students rather than forcing the students.

25. I want my teacher to give me confidence in basic things, e.g. holding needle holder for suturing and scared to put stitch.

Mentoring/Motivation

26. Mentoring should be introduced from 1st year to facilitate and guide in academic and other college related issues.

27. Counselling should be done of the students to increase their self-efficacy.

28. There should be motivational speech in the college for the importance of the ward rotation.

Theme-2 Environment factors

Discipline/Attendance

29. It's a cycle. If you impose ward attendance especially subspecialty wards rotation, then students will go.

30. If a system is devised for attendance and students following peer will attend the ward.

31. Little strictness on attendance must be compulsory.

Theme-3 Students factors

Active participation

32. Students should take active participation.

33. Students should be motivated for active participation.

34. I will encourage the students for bedside clinical training.
Table IV: Frequency of quotes associated with different themes.

\begin{tabular}{|c|c|c|c|}
\hline & $\begin{array}{l}\text { FGD } 1 \\
\mathrm{~N}(\%) \\
\end{array}$ & $\begin{array}{l}\text { FGD } 2 \\
\mathrm{~N}(\%) \\
\end{array}$ & $\begin{array}{c}\text { Both FGDs } \\
\mathrm{N}(\%)\end{array}$ \\
\hline \multicolumn{4}{|l|}{$\begin{array}{l}\text { Frequency of quotes for } \\
\text { "Absenteeism Reasons" }\end{array}$} \\
\hline Faculty related & $49(62)$ & $34(46.58)$ & $83(54.60)$ \\
\hline Curriculum & $7(8.86)$ & $4(5.48)$ & $11(7.24)$ \\
\hline Teaching Inconsistency/controversy & $6(7.59)$ & $5(6.84)$ & $11(7.24)$ \\
\hline No bedside training & $4(5.06)$ & $2(2.73)$ & $6(3.94)$ \\
\hline No practical training & $7(8.86)$ & $7(9.59)$ & $14(9.21)$ \\
\hline Teach theory & $3(3.79)$ & $4(5.47)$ & $7(4.60)$ \\
\hline Teacher discouragement & $7(8.86)$ & $3(4.10)$ & $10(6.57)$ \\
\hline Teacher disinterest & $9(11.39)$ & $6(8.21)$ & $15(9.86)$ \\
\hline Proper schedule & $0(0.00)$ & $3(4.10)$ & $3(1.97)$ \\
\hline Syllabus & $6(7.59)$ & $0(0.00)$ & $6(3.94)$ \\
\hline Environment related & $17(21.50)$ & $26(35.62)$ & $43(28.30)$ \\
\hline Priority of senior class & $3(3.79)$ & $1(1.37)$ & $4(2.63)$ \\
\hline Proper attendance & $0(0.00)$ & $10(13.70)$ & $10(6.57)$ \\
\hline Short time & $3(3.79)$ & $1(1.37)$ & $4(2.63)$ \\
\hline Wastage time & $11(13.92)$ & $14(19.18)$ & $25(16.44)$ \\
\hline Students related factors & $13(16.45)$ & $13(17.80)$ & $26(17.10)$ \\
\hline Pear discouragement & $7(8.86)$ & $4(5.48)$ & $11(7.24)$ \\
\hline Laziness & $6(7.59)$ & $9(12.32)$ & $15(9.86)$ \\
\hline Total & $79(100)$ & $73(100)$ & $152(100)$ \\
\hline \multicolumn{4}{|l|}{$\begin{array}{l}\text { Frequency of quotes for } \\
\text { "Improvement in Absenteeism" }\end{array}$} \\
\hline Faculty related & $44(77.19)$ & $71(92.20)$ & $115(85.82)$ \\
\hline Bedside Teaching & $7(12.28)$ & $13(16.88)$ & $20(14.92)$ \\
\hline Curriculum & $7(12.28)$ & $4(5.19)$ & $11(8.20)$ \\
\hline Faculty training & $5(8.77)$ & $15(19.48)$ & $20(14.92)$ \\
\hline Feedback & $7(12.28)$ & $3(3.89)$ & $10(7.46)$ \\
\hline Less theory & $2(3.50)$ & $9(11.68)$ & $11(8.20)$ \\
\hline Practical training & $6(10.52)$ & $14(18.18)$ & $20(14.92)$ \\
\hline Mentoring & $0(0.00)$ & $6(7.79)$ & $6(4.47)$ \\
\hline Schedule & $10(17.54)$ & $3(3.89)$ & $13(9.70)$ \\
\hline Class test & $0(0.00)$ & $4(5.19)$ & $4(2.98)$ \\
\hline Environment related & $7(12.28)$ & $6(7.79)$ & $13(9.70)$ \\
\hline Compulsory attendance & $3(5.26)$ & $4(5.19)$ & $7(5.22)$ \\
\hline Not compulsory attendance & $3(5.26)$ & $1(1.29)$ & $4(2.98)$ \\
\hline Punctuality and discipline & $1(1.75)$ & $1(1.29)$ & $2(1.49)$ \\
\hline Students related factors & $6(10.52)$ & $0(0.00)$ & $6(4.47)$ \\
\hline Active participation & $6(10.52)$ & $0(0.00)$ & $6(4.47)$ \\
\hline Total & $57(100)$ & 77 (100) & $134(100)$ \\
\hline
\end{tabular}

faculty related improvement as the most quotes, i.e. 115 $(85.82 \%)$ followed by environment and student related factors, i.e. $13(9.70 \%)$ and $6(4.47 \%)$, respectively (Table IV).

On comparison between two FGDs, good students quoted faculty-related factor more than lower grade students, i.e. $49(62 \%)$ vs. $34(46.58 \%)$ but student related factors were same, i.e. $13(16.45 \%)$ vs. 13 $(17.80 \%)$. But lower grade students quoted more environmental related factors, i.e. $26(35.62 \%)$ vs. 17 $(21.50 \%)$ for their absenteeism as compared to higher grade students.

When comparisons of quotes for improvement in absenteeism were made between FGDs then lower 
grade students stressed more on faculty improvement i.e. $71(92.20 \%)$ vs. $44(77.19 \%)$ and negligible improvement of students as in Table IV.

Overall students felt that they did not have any hindrance in attending the subspecialty wards rotation except for teacher related factors and some class tests. They thought subspecialty ward rotation is very necessary for basic orientation of subspecialties. Only few were of the opinion that this course component can be covered in internal medicine and general surgery ward rotations. Most of the students thought their clinical training will be deficient without clinical rotations in subspecialty wards and it should be mandatory for all students.

\section{DISCUSSION}

Absenteeism is a major concern in higher education worldwide. ${ }^{10-12}$ Addressing absenteeism is important in terms of academics as well as fulfillment of responsibilities entrusted on an individual as part of professional development. Failure to address this can result in reduced responsibility in future professional life. ${ }^{13}$ This study highlights faculty related issues as the main reason as overall quotes during discussion were $83(54.60 \%)$. The environmental and student related were $43(28.30 \%)$ and $26(17.10 \%)$, respectively. But students gave suggestions for the rectification of absenteeism more for faculty improvement, i.e. 115 $(85.82 \%)$ and least for students related $6(4.47 \%)$.

Most of the students expressed their interest not only in wards but also in learning. Even students go to some wards without any schedule, where good teaching occurred but no attendance for the students. Faculty related factors, being the most emphasised theme, detailed are ineffective teaching methodology, no proper ward training curriculum (7.24\%) for under graduates, teachers' discouraging (6.57\%) and disinterested attitudes $(9.86 \%)$ leading to little learning and even some students considered going to these subspecialty wards a waste of time (16.44\%) as in Table IV. Didactic classroom like teaching in wards with little bedside practical training $(13.15 \%)$ also encouraged absenteeism (Table IV). Absence of coordination, inconsistency and at a time contradictory clinical method with teaching topic repetitions among the teachers $(7.24 \%)$ was another reason (Table IV). Such type of ineffective methodology has bad impact on learning of medical students with ultimate absenteeism and good students preferring to self-study to utilise time more effectively for academic reasons rather to attend subspecialty ward.14,15 Whereas, poorly performing students either socialise or rest due to their laziness.10 Common reasons for absenteeism in different studies are more likely to be the same as teaching schedule inconvenient, boring teaching style, teacher attitudes and topic/ specialty related, class test/examinations and selfstudy. 12,16,17 Accordingly, certain behaviour and reasons related to faculty and environment in the subspecialty wards in this study would tend to make the students disinterested and gradually enhance absenteeism (Table II). 7,18

This problem of absenteeism can be addressed through improvement in teaching methodology, faculty training, proper curriculum, and improved attendance record keeping (Table III). Bedside training (14.92\%) rather than didactic teaching along with faculty development programme (14.92\%) was recommended. Hands-on training $(14.92 \%)$ of undergraduate medical students results not only in improved learning but also better equips future doctors in domains of knowledge, skills and attitudes.19 Faculty staff have an impact on the attitude of the students in ward attendance and can nurture students' positive behaviour. 20 Accordingly, continuing professional development and motivation was recommended by the students in this study for the prevention of absebteeism. ${ }^{21}$

The outcome of undergraduate medical students' training is ability to produce adequate knowledge and skills for applying in real life. But it is common that absenteeism can affect substantially not only their competency but also on their achievements. ${ }^{22}$ The good performance and competency is very crucial for undergraduate medical students because they will be directly involved in decision-making during life and death situations. ${ }^{23}$ The reasons thus identified in this study needs to be addressed to improve students' exposure of sub-specialties. This qualitative study should be transferable to institutions facing similar issues especially considering this curriculum is applied across Pakistan as per recommendation of Pakistan Medical and Dental Council. ${ }^{1}$ Other factors to be considered for transferability can be done by carefully identifying similarities and differences of institutional environment and student populations.

This study has been carried out in a public-sector institution in southern Punjab, Pakistan on fourth year MBBS students of Quaid-e-Azam Medical College, Bahawalpur and uniquely in-depth mind explores qualitatively the reasons and solutions for subspecialty rotations absenteeism by FGDs. Most of the previous studies have been quantitative cross-sectional survey. $3,4,7,16,24$

There are few limitations of this study as most of the reasons identified in this study are of factors other than students related, which can be considered as part of external attribution. Students may also be reluctant to give true detailed opinion due to confidentiality apprehensions in spite of reassurances given before the FGDs. 


\section{CONCLUSION}

This study found that the main reason of the fourth year medical students' low attendance at subspecialty clinical ward rotation were faculty related factors like improper teaching methodology, absence of a formal curriculum and teacher attitudes leading to little learning and students considering attending these wards is a waste of time. Improvement suggested an applied practical subspecialty curriculum implementation, continuing medical education for faculty development, effective interactive teaching/training strategies, student feedback system and administrative measures like attendance record keeping.

Disclosure: This study was conducted to fulfill the partial requirement of MCPS-Health Professions Education Programme of CPSP.

\section{REFERENCES}

1. Curriculum of MBBS. Pakistan Medical \& Dental Council and Higher Education Commission, Islamabad, Pakistan.2011.

2. Baig LA, Akram D, Ali SK. Development of the communityoriented medical education curriculum of Pakistan: A case report on the national initiative on curriculum development. Educ Health 2006; 19:223-8.

3. Hafeez K, Khan ML-U-Z, Jawaid M, Haroon S. Low attendance in lectures at medical colleges of Karachi - A cross-sectional survey. J Postgrad Med Inst 2014; 28:161-4.

4. Deane RP, Murphy DJ. Student attendance and academic performance in undergraduate obstetrics/gynecology clinical rotations. JAMA 2013; 310:2282-8.

5. Cohall $\mathrm{DH}$, Skeete $\mathrm{D}$. The impact of an attendance policy on the academic performance of first year medical students taking the Fundamentals of Disease and Treatment course. Caribb Teach Scholar 2012; 2:115-23.

6. Massingham $P$, Herrington $T$. Does attendance matter? An examination of student attitudes, participation, performance and attendance. J Univ Teach Learn Pract 2006; 3:3.

7. Bati AH, Mandiracioglu A, Orgun F, Govsa F. Why do students miss lectures? A study of lecture attendance amongst students of health science. Nurse Educ Today 2013; 33:596-601.

8. Burns CA, Lambros MA, Atkinson HH, Russell G, Fitch MT. Preclinical medical student observations associated with later professionalism concerns. Med Teach 2017; 39:38-43.

9. Daelmans H, Hoogenboom R, Donker A, Scherpbier A, Stehouwer C, Van der Vleuten C. Effectiveness of clinical rotations as a learning environment for achieving competences. Med Teach 2004; 26:305-12.
10. Wadesango N, Machingambi S. Causes and structural effects of student absenteeism: a case study of three South African Universities. J Soc Sci 2011; 26:89-97.

11. Kottasz R. Reasons for student non-attendance at lectures and tutorials: An analysis. Investig Univ Teach Learn 2005; 2:5-16.

12. Desalegn AA, Berhan A, Berhan Y. Absenteeism among medical and health science undergraduate students at Hawassa University, Ethiopia. BMC Med Educ 2014; 14:81.

13. Parker M, Luke H, Zhang J, Wilkinson D, Peterson R, Ozolins I. The pyramid of professionalism: seven years of experience with an integrated program of teaching, developing, and assessing professionalism among medical students. Acad Med 2008; 83:733-41.

14. Ganyaupfu EM. Teaching methods and students academic performance. Int J Humanit Soc Sci Invent 2013; 2:29-35.

15. Gul R, Khan HM, Alam SR, Luqman F, Shahab A, Sohail H. Absenteeism among medical undergraduate. J Med Sci 2016; 24:16-8.

16. Alghamdi A, Yamani A, Khalil A, Albarkati B, Alrehili O, Salih M. Prevalence, causes and impacts of absenteeism among medical students at UQU. Education 2016; 6:9-12.

17. Nevins EJ, Moori PL, Alexander L, Richards B, Bleasdale V, Sharma AK. Could attendance at medical school be improved? A prospective study of medical education at the university of Liverpool: Study of attendance at a UK medical school. Med Ed Publish 2016; 5.

18. Obeng-Denteh W, Yeboah EA, Sam C, Monkah JE. The impact of student and teacher absenteeism on student performance at the junior high school: the case of the Kumasi-metro school district. Cont J Educ Res 2011; 4:7-17.

19. Wise MR, Kool B, Sadler L, Peiris-John R, Robb G, Wells S. Teaching quality improvement to medical students: over a decade of experience. N Z Med J 2017; 130:45-52.

20. Gump SE. Guess who's (not) coming to class: Student attitudes as indicators of attendance. Educ Stud 2006; 32:39-46.

21. Baykan Z, Kilinc M, Nacar M. The Attitudes of freshman students in Erciyes University Faculty of Medicine towards Absenteeism. J High Educ Sci 2016; 6:178-85.

22. Shimoff E, Catania AC. Effects of recording attendance on grades in introductory psychology. Teach Psychol 2001; 28: 192-5.

23. Ceria C. Nursing absenteeism and its effects on the quality of patient care. J Nurs Adm 1992; 22:11-38.

24. Rao B, Valleswary K, Nayak M, Rao NL. Reasons for absenteeism among the undergraduate medical students attending for theory classes in Rajiv Gandhi Institute of Medical Sciences (RIMS) Ongole, Prakasam, District of Andhra Pradesh: A self review. J Res Method Educ 2016; 6:11-9. 